\title{
Interleukin-27 augments the inhibitory effects of sorafenib on bladder cancer cells
}

\author{
J.Y. $\mathrm{CaO}^{1 *}$, H.S. Yin ${ }^{1 *}$, H.S. Li ${ }^{2}$, X.Q. Yu ${ }^{2}$ and X. $\mathrm{Han}^{2}$ \\ ${ }^{1}$ Department of Urology, Binzhou Medical University Hospital, Binzhou, China \\ ${ }^{2}$ Department of Gastrointestinal Surgery, Binzhou Medical University Hospital, Binzhou, China
}

\begin{abstract}
Both sorafenib and interleukin-27 (IL-27) are antineoplastic drugs. This study aimed to investigate the synergistic effect of these two drugs on bladder cancer cells. HTB-9 and T24 cells were stimulated with IL-27 (50 ng/mL), sorafenib $(2 \mu \mathrm{M})$ or the synergistic action of these two drugs. The cells without treatment acted as control. Cell proliferation, apoptosis and invasion were measured by bromodeoxyuridine assay, flow cytometry and modified Boyden chamber, respectively. Simultaneously, both modified Boyden chamber and scratch assay were used to assess cell migration. Finally, the phosphorylation levels of key kinases in the Akt/mechanistic target of rapamycin (mTOR)/mitogen-activated protein kinase (MAPK) pathway, and expression levels of matrix metalloproteinase (MMP)-2 and MMP-9 were detected by western blot analysis. Stimulation with IL-27 or sorafenib repressed proliferation, migration and invasion but promoted apoptosis, and the effects were all enhanced by the combination of these two drugs in HTB-9 cells. The effect of the combined treatment on bladder cancer cells was verified in T24 cells. Additionally, the phosphorylation levels of AKT, mTOR and MAPK as well as the expression levels of MMP-2 and MMP-9 were all decreased by a single treatment of IL-27 or sorafenib, and further decreased by the combined treatment of these two drugs. The combination of IL-27 and sorafenib inhibited proliferation, migration and invasion and promoted apoptosis of bladder cancer cells compared with mono-drug treatment. Additionally, the AKT/mTOR/MAPK pathway might be implicated in the functional effects by down-regulations of MMP-2 and MMP-9.
\end{abstract}

Key words: Sorafenib; Interleukin 27; Proliferation; Apoptosis; Invasion; Akt/mTOR/MAPK

\section{Introduction}

Bladder cancer, which is classified as non-muscleinvasive bladder cancer (approximately $70-80 \%$ of patients) and muscle-invasive bladder cancer, ranks fourth among cancers in men and eighth among cancers in women, according to the National Cancer Institute $(1,2)$. Four hundred and thirty thousand new cases of bladder cancer were predicted worldwide in 2012 (3). Based on the stages of neoplasm, several approaches have been applied to treat bladder cancer, including transurethral resection, bacilli Calmette-Guerin instillation, cystectomy with extended lymphadenectomy, and external beam radiotherapy (4). However, the course of therapy is long, expensive and along with great burden (5). Moreover, deaths caused by bladder cancer were estimated to reach 165 thousand worldwide in 2012 (3). Thus, the need of exploring new therapeutic targets for bladder cancer remains urgent.

Sorafenib was first identified as a Raf kinase inhibitor, and then numerous investigations verified that sorafenib is involved in various tumor progression and angiogenesis processes through inhibition of multiple receptor tyrosine kinases (6). Not only the United States Food and Drug
Administration but also the European Medicines Agency have approved the application of sorafenib for treatment of renal cell carcinoma and hepatocellular carcinoma $(7,8)$. Moreover, several phase II clinical trials of sorafenib are being carried out in patients with urothelial carcinomas $(9,10)$. A previous study has reported that the PI3K/Akt/ mTOR pathway plays a crucial role in cancer progression and thus this signaling pathway becomes a therapeutic target for bladder cancer (11). However, another study illustrated that sorafenib could phosphorylate S6K and 4EBP1, which are known as targets of mTOR (12). Considering the conflict reported above, combined drugs are needed to co-function with sorafenib.

Interleukin (IL)-27, which consists of Epstein-Barr virusinduced gene 3 (EBI3, IL-12 p40-related protein) and IL-12 p35-related polypeptide p28, is a heterodimeric cytokine belonging to IL-12/1L-23 family $(13,14)$. Recently, IL-27 was proven to possess multifaceted anti-tumor activity in lung (15), prostate (16), pancreatic (17) and breast cancers (18). In addition, IL-27 has been reported to possess potent antiangiogenic activity (19). Taking into account the same

Correspondence: X. Han: <hanxia0011@126.com> 
effect of sorafenib and IL-27 on anti-tumor and antiangiogenesis, we reasoned that the combination of IL-27 and sorafenib might cooperate synergistically to treat bladder cancer. To test this hypothesis, we examined the influence of sorafenib, IL-27 and the combination of these two factors on cell proliferation, apoptosis, migration and invasion. Furthermore, the involved pathway was also explored.

\section{Material and Methods}

\section{Cell culture and treatment}

Human bladder cancer HTB-9 and T24 cell lines were purchased from American Type Culture Collection (ATCC, USA). Cells were cultured in complete RPMI-1640 medium (Invitrogen, USA) containing 10\% fetal bovine serum (FBS; Gibco, USA) and 1\% penicillin-streptomycin (Sigma, USA) at $37^{\circ} \mathrm{C}$ in a humidified atmosphere of $95 \%$ air and $5 \% \mathrm{CO}_{2}$. Human IL-27 (Sigma) and sorafenib (LC Laboratories, USA) were both dissolved in dimethyl sulfoxide (DMSO; Sigma) and the final concentration of DMSO in all the treatments was below $0.1 \%(\mathrm{v} / \mathrm{v})$. Cells were divided into four groups: cells in the control group were cultured without any treatment; cells in IL-27 group were cultured with IL-27 (50 ng/mL); cells in Sorafenib group were cultured with sorafenib $(2 \mu \mathrm{M})$; and cells in IL-27 + Sorafenib group were cultured with a combination of IL-27 (50 ng/mL) and sorafenib $(2 \mu \mathrm{M})$.

\section{Cell proliferation assay}

Bromodeoxyuridine (BrdU), also termed 5'-bromo-2'deoxyuridine, is incorporated into newly synthesized DNA during proliferation. In our study, a BrdU cell proliferation assay kit (Abcam, USA) was used to evaluate cell proliferation. In brief, cells with a density of $2 \times 10^{4}$ cells/ well were divided into four groups and plated in a 96-well plate. After addition of $20 \mu \mathrm{L}$ of $1 / 500$ diluted BrdU, the cells were cultured for $24 \mathrm{~h}$ and then fixed and denatured. Then, anti-BrdU antibody, peroxidase-conjugate goat antimouse IgG antibody, TMB peroxidase substrate and stop solution were added to each well in that order. As a consequence, the color of positive wells was changed to yellow. The plate was read by a microplate reader (Biorad, USA) at a wavelength of $450 \mathrm{~nm}$.

\section{Apoptosis assay}

Annexin V-FITC/PI apoptosis detection kit (Beijing Biosea Biotechnology, China) was used to assess the apoptosis of treated cells. Briefly, four groups of cells with different treatments were harvested after $24 \mathrm{~h}$ of culture. Then, cells were successively washed by cold phosphatebuffered saline (PBS), suspended in binding buffer and stained with $10 \mu \mathrm{L}$ of Annexin V-FITC and $5 \mu \mathrm{L}$ of propidium iodide (PI) in line with supplier's instructions. Subsequently, an LSR II flow cytometer (BD Biosciences, USA) was used to detect the apoptotic cells with the analysis using FlowJo software (Tree Star, USA).

\section{Migration and invasion assay}

A modified Boyden chamber (Costar-Corning, USA) was used to assess the cell migration accompanied by 8.0- $\mu \mathrm{m}$ pore polycarbonate filter inserts in a 24 -well plate. Briefly, $500 \mu \mathrm{L}$ of complete medium was added in the lower chamber. Then, four groups of cells $\left(5 \times 10^{4}\right.$ cells/ well) resuspended in $300 \mu \mathrm{L}$ of serum-free medium were added onto the upper chamber. The plate was then put into an incubator at $37^{\circ} \mathrm{C}$ with $5 \% \mathrm{CO}_{2}$ for $24 \mathrm{~h}$. After that, non-migrated cells located on the upper surface of the membrane were carefully removed by a cotton swab. Simultaneously, the migrated cells were fixed with methanol and stained with crystal violet (Beyotime, China). After being photographed by an Olympus IX51 inverted fluorescence microscope equipped with a digital camera (Olympus, USA), migrated cells were counted from 10 random fields at $200 \times$ magnification. The cell invasion assay was performed similarly to cell migration except that the transwell inserts were pre-coated with matrigel.

\section{Scratch assay}

Cells were seeded into a 6-well plate and cultured overnight. When the cells reached $60-70 \%$ confluence, the monolayers were scratched by a $100 \mu \mathrm{L}$ pipette tip, followed by rinsing with PBS thrice to remove detached cells and imaging with an Olympus microscope (Olympus). Then, the culture mediums were respectively changed to complete medium or complete medium supplemented with IL-27, sorafenib or a combination of IL-27 and sorafenib. The cells were then incubated for $48 \mathrm{~h}$ at $37^{\circ} \mathrm{C}$ with $5 \%$ $\mathrm{CO}_{2}$. After removal of culture medium, the scratched areas were imaged again to observe the wound gap.

\section{Western blot analysis}

After treatments, the proteins from the four groups of cells were respectively extracted with RIPA lysis (Beyotime) containing protease and phosphatase inhibitor (Applygen Technologies Inc., China). The amount of proteins was determined by a Bicinchoninic acid (BCA) protein assay kit (Beyotime). Then, proteins were subjected to $12 \%$ sodium dodecyl sulfate-polyacrylamide gel electrophoresis (SDSPAGE) gel, which was followed by transferring to nitrocellulose membranes. After being blocked with $5 \%$ non-fat milk for $2 \mathrm{~h}$ at room temperature, the membranes were respectively incubated with primary antibodies against Akt (4691), phosphorylated Akt (p-Akt, 4060), mechanistic target of rapamycin (mTOR, 2972), phosphorylated mTOR (p-mTOR, 5536), mitogen-activated protein kinase (MAPK, 8690), phosphorylated MAPK (p-MAPK,4511), matrix metalloproteinase (MMP)-2 (13132), MMP-9 (13667) and $\beta$-actin (4970) (all from Cell Signaling Technology, USA) at $4^{\circ} \mathrm{C}$ overnight. Then, membranes were incubated with HRPmarked secondary antibody at room temperature for $1.5 \mathrm{~h}$. The membranes carrying proteins and blots were subjected to ECL detection kit (Pierce, USA) to be visualized, followed by analysis with Quantity One 1-D Analysis Software (Bio-Rad). 


\section{Statistical analysis}

Results are reported as the mean \pm SE. Statistical analysis was performed using Graphpad Prism 5 software (GraphPad, USA). The P-values were calculated using the unpaired two-tailed $t$-test. A P value of $<0.05$ was considered to indicate a statistically significant difference.

\section{Results}

\section{IL-27 enhanced the suppression of sorafenib on cell proliferation in HTB-9 cells}

BrdU assay was performed to assess cell proliferation following stimulation of IL-27, sorafenib or a combination

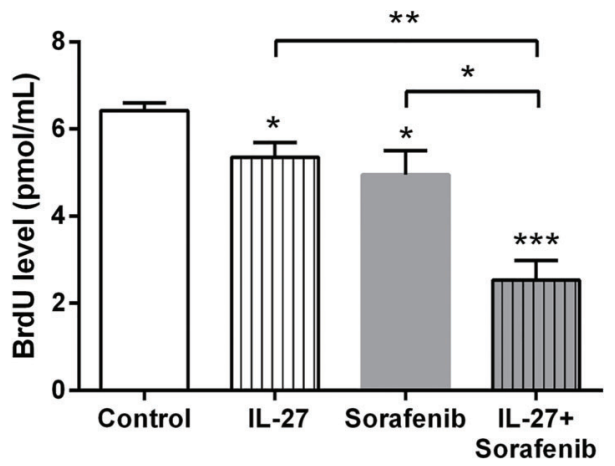

Figure 1. Effect of IL-27 $(50 \mathrm{ng} / \mathrm{mL})$ and sorafenib $(2 \mu \mathrm{M})$ alone or their combination on cell proliferation of HTB-9 cells, performed by BrdU assay. Cells cultured with blank medium acted as control. Data are reported as the mean \pm SE of 4 independent experiments. ${ }^{*} \mathrm{P}<0.05 ;{ }^{* *} \mathrm{P}<0.01 ;{ }^{* * *} \mathrm{P}<0.001$ compared to control unless indicated otherwise ( $t$-test). IL-27: interleukin 27; BrdU: bromodeoxyuridine. of both on HTB-9 cells. Figure 1 shows that the cell proliferation was markedly inhibited by a single treatment of IL-27 or sorafenib (both $\mathrm{P}<0.05$ compared to control), and the inhibitory effect was further enhanced by drug combination ( $P<0.001$ compared to control), resulting in obvious decrease of cell proliferation compared with single treatments of IL-27 $(P<0.01)$ or sorafenib $(P<0.05)$. Thus, we concluded that IL-27 augmented the suppression of sorafenib on proliferation of HTB-9 cells.

\section{IL-27 augmented the effect of sorafenib on cell apoptosis in HTB-9 cells}

We then evaluated the effect of IL-27, sorafenib, or their combination on cell apoptosis by flow cytometry. As shown in Figure 2, the number of apoptotic cells was significantly increased by a single stimulation of IL-27 or sorafenib (both $\mathrm{P}<0.05$ compared to control). The number of apoptotic cells was further increased by the drug combination ( $P<0.001$ compared to control), resulting in a significant difference compared to single treatment of IL-27 $(P<0.001)$ or sorafenib $(P<0.01)$. These results indicated that IL-27 augmented the effect of sorafenib on apoptosis of HTB-9 cells.

\section{IL-27 in combination with sorafenib augmented the repression of cell migration and invasion in HTB-9 cells}

The influence on cell migration and invasion was further assessed by modified Boyden chamber. As shown in Figure $3 A-D$, both migration and invasion were repressed by a single treatment of IL-27 or sorafenib (all $\mathrm{P}<0.05$ compared to control). Additionally, repression was obviously enhanced by co-stimulation of IL-27 and sorafenib (both $\mathrm{P}<0.05$ for cell invasion and both $\mathrm{P}<0.01$ for cell
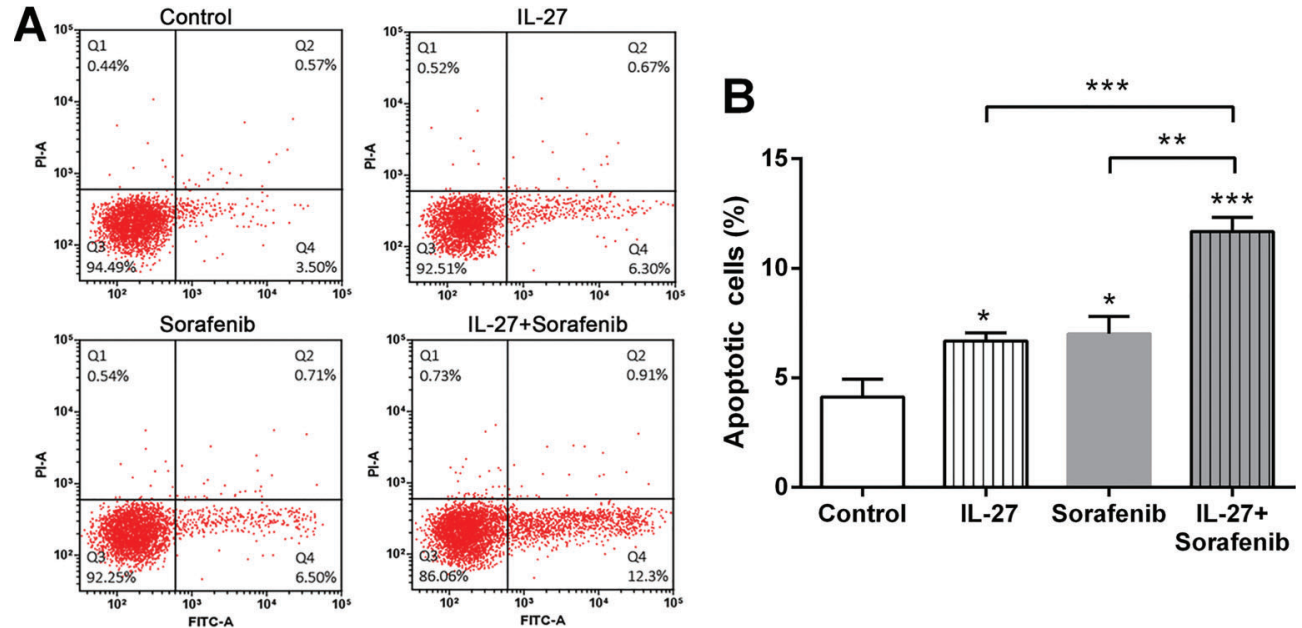

Figure 2. Effect of IL-27 (50 ng/mL) and sorafenib $(2 \mu \mathrm{M})$ alone or their combination on HTB-9 cell apoptosis assessed by flow cytometry $(A, B)$. Cells cultured with blank medium acted as control. Data are reported as the mean $\pm \mathrm{SE}$ of 4 independent experiments. ${ }^{*} \mathrm{P}<0.05$; ${ }^{* *} \mathrm{P}<0.01 ;{ }^{* * *} \mathrm{P}<0.001$ compared to control unless indicated otherwise ( $t$-test). IL-27: interleukin 27. 

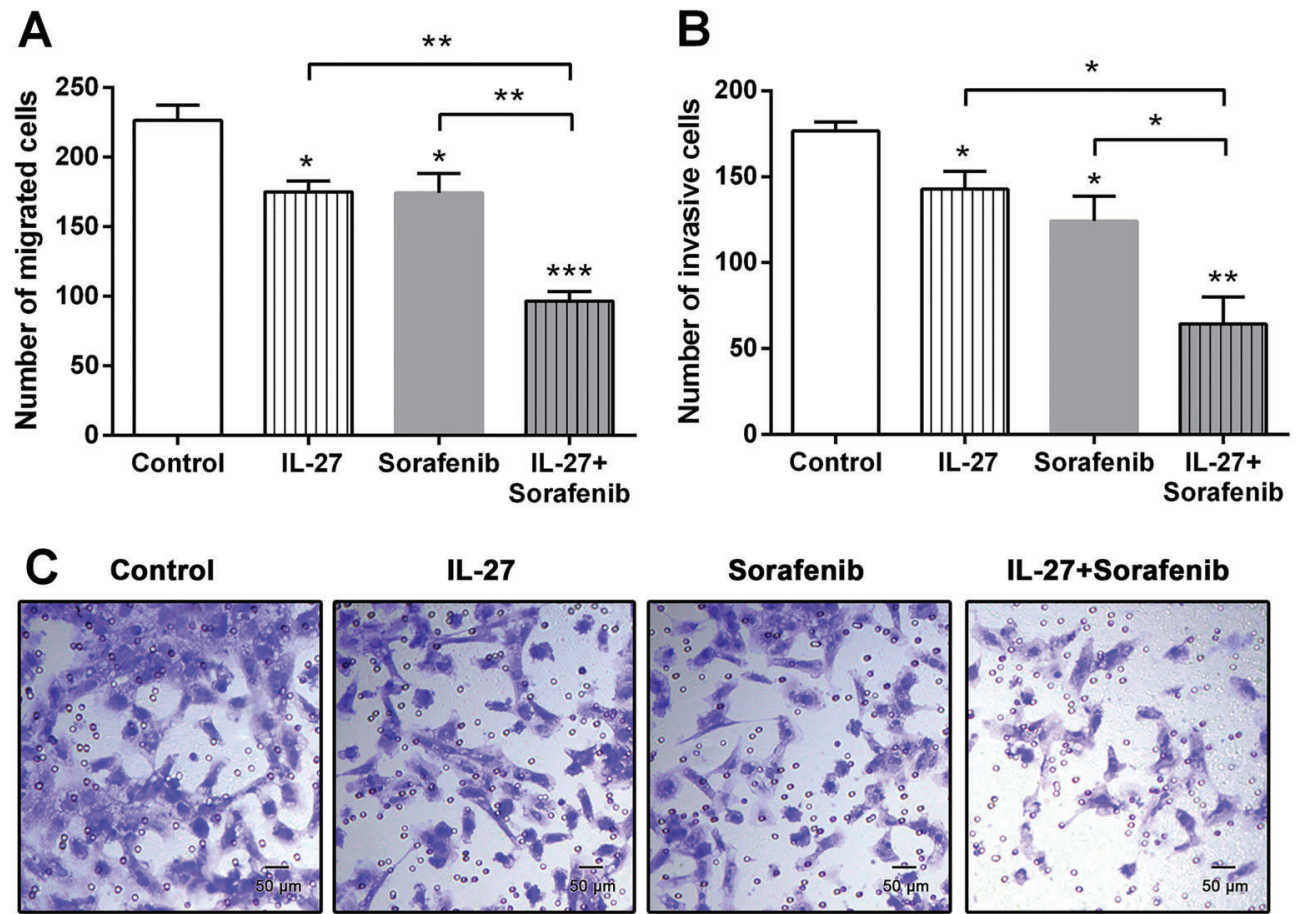

\section{IL-27+Sorafenib}

D Control

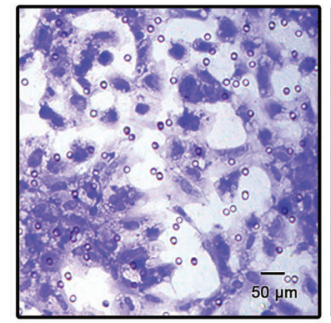

IL-27

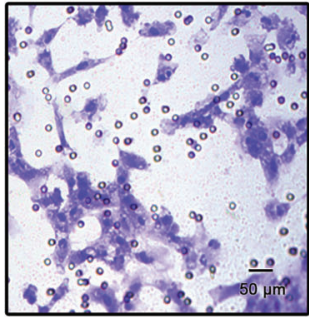

Sorafenib

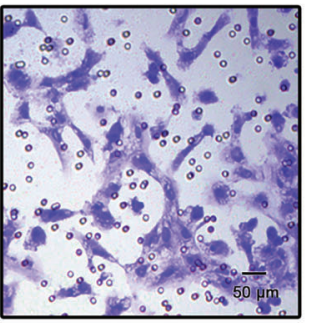

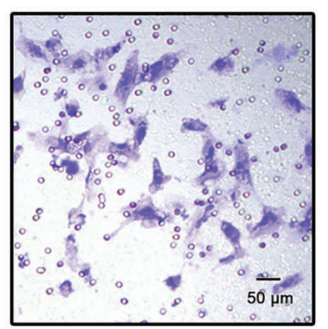

IL-27+Sorafenib

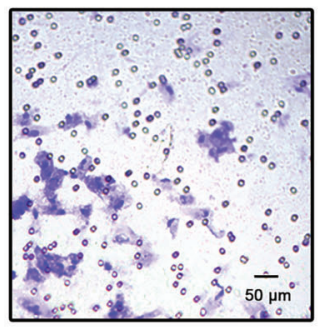

Figure 3. Effect of IL-27 $(50 \mathrm{ng} / \mathrm{mL})$ and sorafenib $(2 \mu \mathrm{M})$ alone or combination on HTB-9 cell migration $(A)$ and invasion $(B)$, assessed by modified Boyden chamber. Cells cultured with blank medium acted as control. $C$, Representative photos of the cell migration assay, and $D$, the cell invasion assay. Data are reported as the mean $\pm \mathrm{SE}$ of 3 independent experiments. ${ }^{*} \mathrm{P}<0.05 ;{ }^{* *} \mathrm{P}<0.01$; ${ }^{* * *} \mathrm{P}<0.001$ compared to control unless indicated otherwise (t-test). IL-27: interleukin 27.

migration compared to single treatment). The data demonstrated that IL-27 augmented the repression of sorafenib on migration and invasion of HTB-9 cells.

\section{IL-27 in combination with sorafenib augmented the inhibition of wound closure in HTB-9 cells}

The scratch assay is reported to be a convenient and inexpensive method for cell migration measurement (20). In this study, we also employed the scratch assay to determine the effect of IL-27, sorafenib, or combination of both on wound closure ability. The results in Figure 4 illustrate that single treatment of IL-27 or sorafenib inhibited wound closure (both $\mathrm{P}<0.05$ compared to control) and co-treatment with these two compounds remarkably enhanced the inhibition ( $P<0.01$ compared to control), indicating that the combined treatment of sorafenib with IL-27 enhanced inhibition of cell migration in HTB-9 cells.

Effect of single or combined treatments of IL-27 and sorafenib on T24 cells was the same as that on HTB-9 cells

To verify the specific influence of combined treatment with IL-27 and sorafenib on bladder cancer cells, the alterations of cell proliferation, apoptosis and migration were all assessed in another bladder cancer cell line, T24 cells, after stimulation. As shown in Figure 5A and C, cell proliferation and migration were both markedly inhibited by the single treatments (all $\mathrm{P}<0.05$ compared to control), and were further inhibited by co-stimulation of IL-27 and sorafenib $(\mathrm{P}<0.001$ for cell proliferation or $\mathrm{P}<0.01$ for cell 


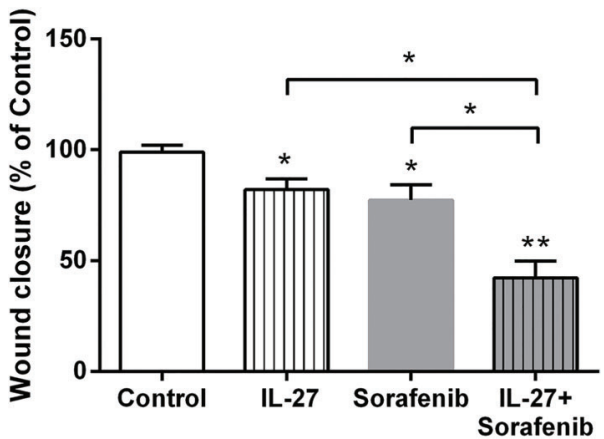

Figure 4. Effect of IL-27 (50 ng/mL) and sorafenib $(2 \mu \mathrm{M})$ alone or their combination on wound closure of HTB-9 cells, measured by the scratch assay. Cells cultured with blank medium acted as control. Data are reported as the mean \pm SE of 3 independent experiments. ${ }^{*} \mathrm{P}<0.05 ;{ }^{* *} \mathrm{P}<0.01$ compared to control unless indicated otherwise (t-test). IL-27: interleukin 27. migration compared to control). Compared with single treatments, combined treatment significantly enhanced the inhibitory effects on proliferation (both $P<0.01$ ) and migration (both $\mathrm{P}<0.05$ ). Conversely, cell apoptosis was markedly increased by single treatments (both $P<0.05$ ), and further increased by combined treatment $(P<0.01)$ compared to control (Figure 5B). Furthermore, combined treatment obviously promoted cell apoptosis compared to single treatment (both $\mathrm{P}<0.05$ ). Taken together, we concluded that combined treatment of sorafenib and IL-27 augmented the effect of single treatments on T24 cells.

\section{IL-27 augmented the inactivation of Akt/mTOR/MAPK pathway mediated by sorafenib through down- regulation of MMP-2 and MMP-9}

The protein expression levels of key kinases and downstream proteins involving in Akt/mTOR/MAPK pathway were assessed by western blot analysis. As shown in
A

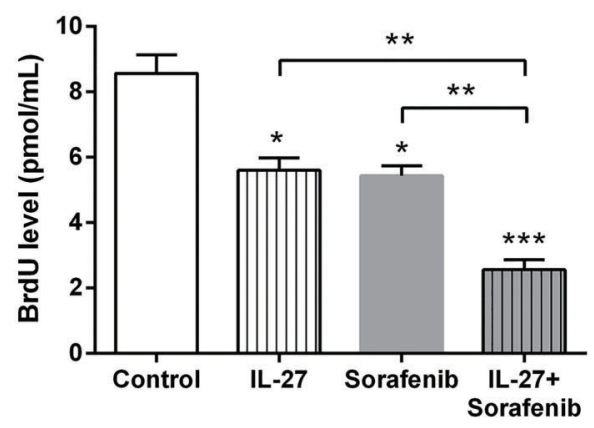

B

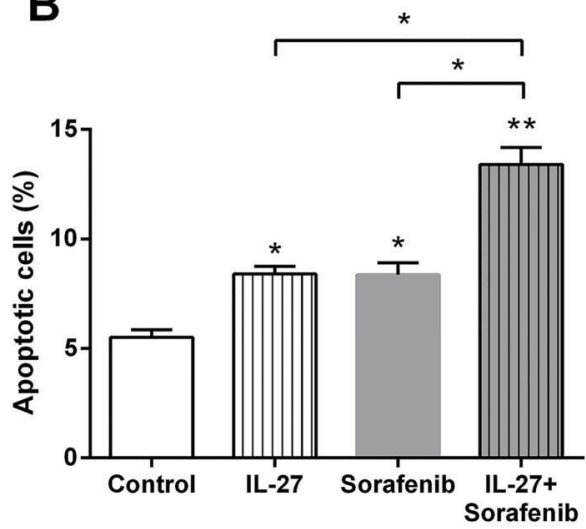

C
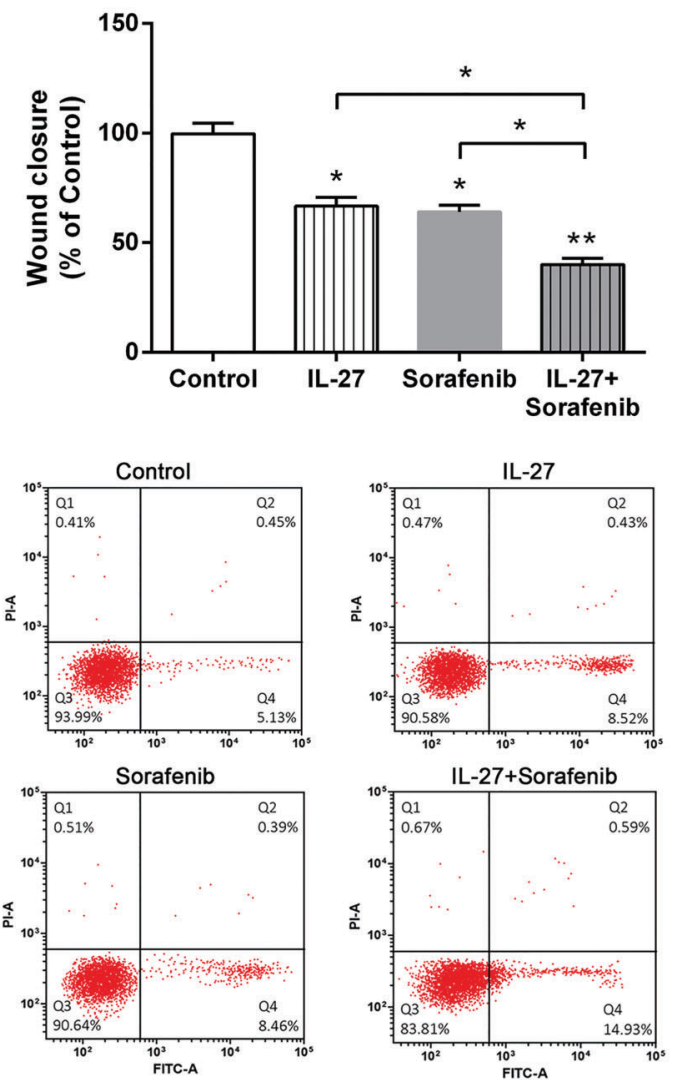

Figure 5. Effect of IL-27 $(50 \mathrm{ng} / \mathrm{mL})$ and sorafenib $(2 \mu \mathrm{M})$ alone or their combination on T24 cells. Cells cultured with blank medium acted as control. $A$, Cell proliferation by BrdU assay. $B$, Cell apoptosis by flow cytometry. $C$, Cell migration by scratch assay. Data are reported as the mean $\pm \mathrm{SE}$ of 3 independent experiments. ${ }^{*} \mathrm{P}<0.05 ;{ }^{* \star} \mathrm{P}<0.01 ;{ }^{* \star *} \mathrm{P}<0.001$ compared to control unless indicated otherwise (t-test). IL-27: interleukin 27; BrdU: bromodeoxyuridine. 
A Control IL-27 Sorafenib IL-27+Sorafenib
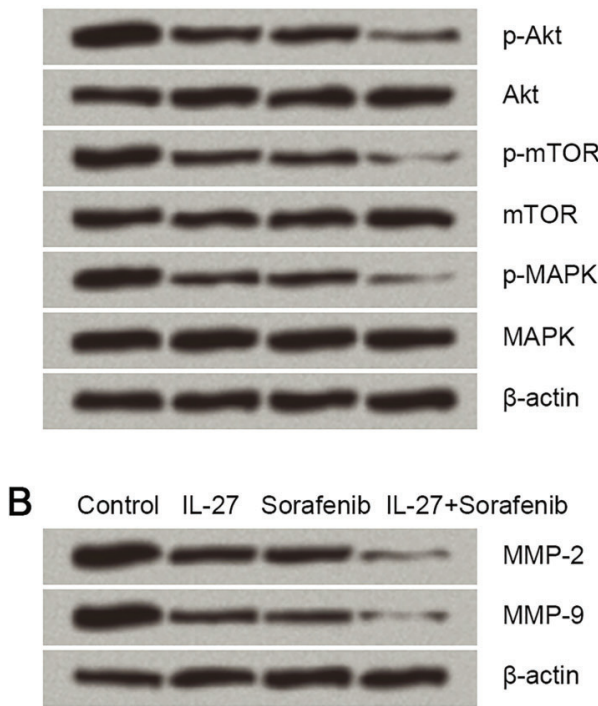

Figure 6. Effect of IL-27 (50 ng/mL) and sorafenib $(2 \mu \mathrm{M})$ alone or in combination on Akt/mTOR/MAPK signaling pathway on HTB-9 cells. Cells cultured with blank medium acted as control. Protein expression was assessed by western blot analysis. $A$, Expression of key kinases involved in the Akt/mTOR/MAPK pathway, and $B$, of downstream proteins involved in the pathway. IL-27: interleukin 27; mTOR: mechanistic target of rapamycin; MAPK: mitogenactivated protein kinase; MMP: matrix metalloproteinase.

Figure 6A, p-Akt, p-mTOR and p-MAPK were all downregulated by single simulation of $\mathrm{IL}-27$ or sorafenib, and the down-regulations were further enhanced by the combined treatment. Moreover, the downstream MMP-2 and MMP-9 were mediated similarly as key kinases involving in Akt/mTOR/MAPK pathway (Figure 6B). Therefore, we speculate that IL-27 augmented the inactivation of Akt/ mTOR/MAPK pathway mediated by sorafenib through down-regulation of MMP-2 and MMP-9.

\section{Discussion}

A previous study has reported that sorafenib in combination with sunitinib malate may be beneficial for treatment of advanced bladder cancer as these two drugs have been proven to prevent tumor growth through repression of angiogenesis (21). Based on the inhibition of IL-27 on tumor angiogenesis, we wished to study the combined effect of IL-27 and sorafenib on bladder cancer. In our study, we interestingly found that IL-27 or sorafenib could inhibit cell proliferation, migration and invasion while promoted cell apoptosis of bladder cancer cells, and the combination of these two drugs significantly augmented the influence in HTB-9 cells. Then, we also verified these influences in another human bladder cancer cell line, T24 cells. Moreover, we also found that expression levels of p-Akt, p-mTOR, p-MAPK, MMP-2 and MMP-9 were all down-regulated by the single simulation of IL-27 or sorafenib, and further down-regulated by the combined simulation.

Sorafenib has been well studied on cell proliferation, apoptosis, migration and invasion in various cell types. Su et al. reported that sorafenib decreased proliferation and induced apoptosis of prostate cancer cells (22). Ha et al. (23) reported that sorafenib inhibited migration and invasion of hepatocellular carcinoma cells. In terms of IL-27, gene therapy of IL-27 could efficiently reduce prostate tumor cell growth in mice (24). Additionally, IL-27 is also reported to promote cell apoptosis in human pancreatic carcinoma Aspc1 cells (25). Another study also claimed that IL-27 inhibited in vitro cell migration of non-small cell lung cancer, accompanied by elevated expression of epithelial markers (26). The results in our study are in agreement with the reports described above. To our knowledge, the combined effect of IL-27 and sorafenib has not been well stated. In our present study, we first explored the synergistic effect of these two drugs and surprisingly discovered that the anti-proliferative, proapoptotic, anti-migration, and anti-invasive effects were all enhanced in HTB-9 cells, which were also verified in T24 cells, indicating the potential application of combination drug therapy for bladder cancer.

Accumulating evidence has demonstrated that the Akt/mTOR/MAPK pathway plays a pivotal role in multiple cellular processes, such as cell proliferation, apoptosis, and migration $(27,28)$. It has already been mentioned that $\mathrm{Akt} / \mathrm{mTOR}$ signaling pathway is activated in bladder tumor sample, emphasizing the importance of this pathway in the progression of urothelial carcinoma and making this pathway become a potential target (29). Results of Moon and colleagues suggested that the possible crosstalk between Akt/mTOR and MAPK/ERK pathway might help NVP-EBZ235 and cisplatin combination therapy treat bladder cancer (30). Therefore, we further studied the expression levels of key kinases involved in Akt/mTOR/MAPK pathway. Here, the downregulations indicated that the synergistic action of IL-27 and sorafenib efficaciously inhibited the activation of Akt/ mTOR/MAPK pathway. Therefore, we speculated that the synergistic action of these two drugs might affect bladder cancer cells by inactivation of Akt/mTOR/MAPK pathway.

As reported previously, MMPs degrade the basement membrane and extra cellular matrix, and thereby create space for cell migration and invasion (31). MMPs also participate in maturation and liberation of substantial growth factors (32). In hepatocellular carcinoma cells, sorafenib has been reported to inhibit migration and invasion through suppression of MMPs expression (23). Specifically, MMP-2 and MMP-9 inhibitor, termed 5a, has been proven to enhance apoptosis in cancer cells (33). Chen et al. (34) demonstrated AKT/mTOR pathway was associated with invasion and metastasis of 
hepatocellular carcinoma through MMP-9. As a consequence, we finally analyzed the expression levels of MMP-2 and MMP-9 and found that both were remarkably down-regulated by single treatment of IL-27 or sorafenib, and the decreases were augmented by synergistic action. Therefore, we draw the conclusion that IL-27 might augment the inactivation of Akt/mTOR/MAPK pathway mediated by sorafenib through down-regulation of MMP-2 and MMP-9.

\section{References}

1. Kirkali Z, Chan T, Manoharan M, Algaba F, Busch C, Cheng $\mathrm{L}$, et al. Bladder cancer: epidemiology, staging and grading, and diagnosis. Urology 2005; 66: 4-34, doi: 10.1016/j.urology. 2005.07.062.

2. Nielsen ME, Smith AB, Meyer AM, Kuo TM, Tyree S, Kim WY, et al. Trends in stage-specific incidence rates for urothelial carcinoma of the bladder in the United States: 1988 to 2006. Cancer 2014; 120: 86-95, doi: 10.1002/cncr.28397.

3. Antoni S, Ferlay J, Soerjomataram I, Znaor A, Jemal A, Bray F. Bladder cancer incidence and mortality: A global overview and recent trends. Eur Urol 2017; 71: 96-108, doi: 10.1016/ j.eururo.2016.06.010

4. Bellmunt J, Orsola A, Wiegel T, Guix M, De Santis M, Kataja V. Bladder cancer: ESMO Clinical Practice Guidelines for diagnosis, treatment and follow-up. Ann Oncol 2011;22 (Suppl 6):vi45-vi49, doi: 10.1093/annonc/mdr376.

5. Danna BJ, Metcalfe MJ, Wood EL, Shah JB. Assessing symptom burden in Bladder cancer: An overview of Bladder cancer specific health-related quality of life instruments. Bladder Cancer 2016; 2: 329-340, doi: 10.3233/BLC-160057.

6. Wilhelm SM, Adnane L, Newell P, Villanueva A, Llovet JM, Lynch M. Preclinical overview of sorafenib, a multikinase inhibitor that targets both Raf and VEGF and PDGF receptor tyrosine kinase signaling. Mol Cancer Ther 2008; 7: 31293140, doi: 10.1158/1535-7163.MCT-08-0013.

7. Thomas L, Lai SY, Dong W, Feng L, Dadu R, Regone RM, et al. Sorafenib in metastatic thyroid cancer: a systematic review. Oncologist 2014; 19: 251-258, doi: 10.1634/theoncologist.2013-0362.

8. Cheng AL, Kang YK, Chen Z, Tsao CJ, Qin S, Kim JS, et al. Efficacy and safety of sorafenib in patients in the AsiaPacific region with advanced hepatocellular carcinoma: a phase III randomised, double-blind, placebo-controlled trial. Lancet Oncol 2009;10: 25-34, doi: 10.1016/S1470-2045(08) 70285-7.

9. Sridhar SS, Winquist E, Eisen A, Hotte SJ, Mcwhirter E, Tannock IF, et al. A phase II trial of sorafenib in first-line metastatic urothelial cancer: a study of the PMH Phase II Consortium. Invest New Drugs 2011; 29: 1045-1049, doi: 10.1007/s10637-010-9408-4.

10. Dreicer R, Li H, Stein M, DiPaola R, Eleff M, Roth BJ, et al. Phase II Trial of Sorafenib (BAY43-9006) in patients with advanced urothelial cancer (E1804): A Trial of the Eastern Cooperative Oncology Group. Cancer 2009; 115: 4090-4095, doi: $10.1002 /$ cncr.24467.

11. Ching CB, Hansel DE. Expanding therapeutic targets in bladder cancer: the PI3K|[sol]|Akt|[sol]|mTOR pathway.
To summarize, IL-27 or sorafenib alone inhibited proliferation, migration and invasion and promoted apoptosis of bladder cancer cells, and the effects were augmented by their synergistic action. Furthermore, this might be attributed to inhibition of Akt/mTOR/MAPK signaling pathway through down-regulations of MMP-2 and MMP-9. The application of the combined treatment possesses significant advantages compared with mono-drug, making it a potential therapeutic strategy for bladder cancer.

Lab Invest 2010; 90: 1406-1414, doi: 10.1038/labinvest. 2010.133.

12. Huynh $\mathrm{H}$, Ngo VC, Koong HN, Poon D, Su PC, Thng $\mathrm{CH}$, et al. Sorafenib and rapamycin induce growth suppression in mouse models of hepatocellular carcinoma. $J$ Cell Mol Med 2009; 13: 2673-2683, doi: 10.1111/j.1582-4934.2009. 00692.x.

13. Pflanz S, Timans JC, Cheung J, Rosales R, Kanzler H, Gilbert J, et al. IL-27, a heterodimeric cytokine composed of $\mathrm{EBI} 3$ and p28 protein, induces proliferation of naive CD4 + T cells. Immunity 2002; 16: 779-790, doi: 10.1016/ S1074-7613(02)00324-2.

14. Yoshida H, Miyazaki Y, Yoshiyuki M. Regulation of immune responses by interleukin-27. Immun Rev 2008; 226: 234-247, doi: 10.1111/j.1600-065X.2008.00710.x.

15. Ho MY, Leu SJ, Sun GH, Tao MH, Tang SJ, Sun KH. IL-27 directly restrains lung tumorigenicity by suppressing cyclooxygenase-2-mediated activities. J Immunol 2009; 183: 62176226, doi: 10.4049/jimmunol.0901272.

16. Di Carlo E, Sorrentino C, Zorzoli A, Di Meo S, Tupone MG, Ognio $\mathrm{E}$, et al. The antitumor potential of Interleukin-27 in prostate cancer. Oncotarget 2013; 5: 10332-10341, doi: 10.18632/oncotarget.1425.

17. Yao L, Wang M, Niu Z, Liu Q, Xiang G, Li Z, et al. Interleukin27 inhibits malignant behaviors of pancreatic cancer cells by targeting M2 polarized tumor associated macrophages. Cytokine 2017; 89: 194-200, doi: 10.1016/j.cyto.2015. 12.003.

18. Lu D, Zhou X, Yao L, Liu C, Jin F, Wu Y. Clinical implications of the interleukin 27 serum level in breast cancer. $J$ Invest Med 2014; 62: 627-631, doi: 10.2310/JIM.000000000000 0046.

19. Shimizu M, Shimamura M, Owaki T, Asakawa M, Fujita K, Kudo $\mathrm{M}$, et al. Antiangiogenic and antitumor activities of IL-27. J Immunol 2006; 176:7317-7324, doi: 10.4049/ jimmunol.176.12.7317.

20. Liang CC, Park AY, Guan JL. In vitro scratch assay : a convenient and inexpensive method for analysis of cell migration in vitro. Nat Protoc 2007; 2: 329-333, doi: 10.1038/ nprot.2007.30.

21. Silay MS, Miroglu C. Sunitinib malate and sorafenib may be beneficial at the treatment of advanced bladder cancer due to their anti-angiogenic effects. Med Hypotheses 2007; 69: 892-895, doi: 10.1016/j.mehy.2007.01.065.

22. Su JO, Erb HHH, Hobisch A, Culig Z. Sorafenib decreases proliferation and induces apoptosis of prostate cancer cells by inhibition of the androgen receptor and Akt signaling 
pathways. Endocr Relat Cancer 2012; 19: 305-319, doi: 10.1530/ERC-11-0298.

23. Ha TY, Hwang S, Moon KM, Won YJ, Song GW, Kim N, et al. Sorafenib inhibits migration and invasion of hepatocellular carcinoma cells through suppression of matrix metalloproteinase expression. Anticancer Res 2015; 35: 1967-1976.

24. Zolochevska O, Xia X, Williams BJ, Ramsay A, Li S, Figueiredo ML. Sonoporation delivery of interleukin-27 gene therapy efficiently reduces prostate tumor cell growth in vivo. Human Gene Ther 2011; 22: 1537-1550, doi: 10.1089/hum. 2011.076.

25. Liu LH, Hao GZ, Zhang C, Ai J, Shao LL, Shan BE. IL-27 promotes apoptosis of human pancreatic carcinoma Aspc1 cells. Chinese J Cancer Biother 2010; 17: 634-638.

26. Kachroo P, Lee MH, Zhang L, Baratelli F, Lee G, Srivastava MK, et al. IL-27 inhibits epithelial-mesenchymal transition and angiogenic factor production in a STAT1-dominant pathway in human non-small cell lung cancer. $J$ Exper Clin Cancer Res 2013; 32: 1-14, doi: 10.1007/s00432-0121351-7.

27. Luo M, Liu Q, He M, Yu Z, Pi R, Li M, et al. Gartanin induces cell cycle arrest and autophagy and suppresses migration involving $\mathrm{PI} / 3 \mathrm{~K} / \mathrm{Akt} / \mathrm{mTOR}$ and MAPK signalling pathway in human glioma cells. J Cell Mol Med 2017; 21: 46-57, doi: $10.1111 / \mathrm{jcmm} .12937$.

28. Lim W, Jeong W, Song G. Delphinidin suppresses proliferation and migration of human ovarian clear cell carcinoma cells through blocking AKT and ERK1/2 MAPK signaling pathways. Mol Cell Endocrinol 2015; 422: 172-181, doi: 10.1016/j.mce.2015.12.013.

29. Houédé N, Pourquier P. Targeting the genetic alterations of the PI3K-AKT-mTOR pathway: Its potential use in the treatment of bladder cancers. Pharmacol Ther 2014; 145: 1-18, doi: 10.1016/j.pharmthera.2014.06.004.

30. Moon du G, Lee SE, Oh MM, Lee SC, Jeong SJ, Hong SK, et al. NVP-BEZ235, a dual PI3K/mTOR inhibitor synergistically potentiates the antitumor effects of cisplatin in bladder cancer cells. Int J Oncol 2014; 45: 1027-1035, doi: 10.3892/ ijo.2014.2505.

31. Kim JW. Effect of nitric oxide on the expression of matrix metalloproteinase and its association with migration of cultured trabecular meshwork cells. Korean $\mathrm{J}$ Ophthalmol 2016; 30: 66-75, doi: 10.3341/kjo.2016.30.1.66.

32. Babykutty S, Suboj P, Srinivas P, Nair AS, Chandramohan K, Gopala S. Insidious role of nitric oxide in migration/invasion of colon cancer cells by upregulating MMP-2/9 via activation of cGMP-PKG-ERK signaling pathways. Clin Exper Metastasis 2012; 29: 471-492, doi: 10.1007/s10585-012-9464-6.

33. Nyormoi O, Mills L, Bareli M. An MMP-2/MMP-9 inhibitor, 5a, enhances apoptosis induced by ligands of the TNF receptor superfamily in cancer cells. Cell Death Differ 2003; 10 : 558-569, doi: 10.1038/sj.cdd.4401209.

34. Chen J S, Wang Q, Fu XH, Huang XH, Chen XL, Cao LQ et al.: Involvement of PI3K/PTEN/AKT/mTOR pathway in invasion and metastasis in hepatocellular carcinoma: Association with MMP-9. Hepatol Res 2009; 39: 177-186, doi: 10.1111/j.1872-034X.2008.00449.x. 